\title{
Prognosis of falls in old people at home
}

\author{
D. WILD, U. S. L. NAYAK, AND B. ISAACS \\ From the Department of Geriatric Medicine, University of Birmingham
}

SUMmARY One hundred and twenty-five people aged 65 and over in the Birmingham area who fell at home were followed up for one year after the fall had been reported by the general practitioner. They were compared with 125 control subjects matched for age and sex and drawn from the same doctors' lists. Two months after the fall, one control and 11 fallers had died. One year after the fall, eight controls and 32 fallers had died. The main factor associated with increased mortality was impaired mobility before the index fall.

The generally held belief that a fall by an old person at home is likely to be followed by a period of deterioration does not seem to have been documented; nor is it known whether the fall causes the deterioration or whether the fall is a manifestation of deteriorating health. In the present study, people aged 65 and over who fell in their own homes were followed up for one year after the fall and compared with an age- and sex-matched control group in respect of mortality, health, and social status.

\section{Material and methods}

One hundred and twenty-five persons aged 65 and over who had fallen in or immediately adjacent to their normal places of residence were notified by their general practitioners (GPs) to a research nurse. They were visited at home and data were recorded on their physical, mental, and social status. Similar information was collected from an age- and sex-matched control group drawn from the lists of the same GPs. Details of the methods used have been given elsewhere. ${ }^{1}$ Follow-up visits were undertaken three and 12 months later by the same research nurse. All surviving subjects were traced and all gave interviews. Information on those who had died was obtained from general practice and hospital records, and death certificate information from the registrar.

\section{Results}

\section{MORT A LITY}

The number of fallers and controls who died in the year after the index fall, and the interval between the fall and death, are shown in the Figure. Two months after the fall, 11 fallers and one control had died. One year after, 32 fallers and eight controls had died. Thus, while the steepest divergence occurred in the first two months after the fall, the curves did not become parallel throughout the year of observation;

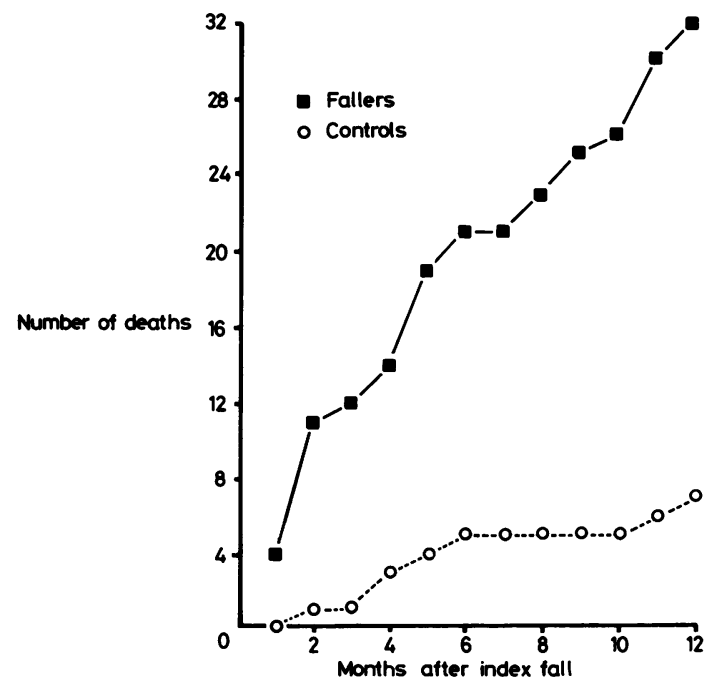

Figure Cumulative mortality in 125 fallers and 125 controls in 12 months after index fall

and fallers continued to die at a much higher rate than controls. Two-thirds of the deaths in fallers and one-third of those in controls took place in hospital. CAUSE OF DEATH

The principal causes of death, as recorded on the death certificates, are shown in Table 1 . The listed causes, which included cardiovascular and cerebrovascular disease, bronchopneumonia and carcinoma, were similar in fallers and in controls, and threw no further light on the mechanism of the falls. No faller who suffered a fracture died in the year after the index fall. Only two post-mortem examinations were conducted on fallers and none on controls but these added no information that explained the cause of the falls. 
Table 1 Principal causes of death as recorded on the death certificates

\begin{tabular}{lcl}
\hline Cause & Fallers & Controls \\
\hline Cerebral vascular accident & 7 & 2 \\
Bronchopneumonia & 12 & 3 \\
Carcinoma & 3 & 1 \\
Congestive cardiac failure & 5 & 1 \\
Myocardial infarction & 5 & 1 \\
& & \\
Total & 32 & 8 \\
\hline
\end{tabular}

FACTORS THAT INFLUENCED MORTALITY

The relationship between death within one year of the fall and the age and sex of the subjects is shown in Table 2. Half of the male fallers aged 75-84, and all of those aged 85 and over, died within one year, compared with only one death in a male control. The mortality of female fallers showed a similar but less drastic pattern. One fifth of those aged 75-84, and one quarter of those aged 85 and over, died within one year, compared with one in 20 controls aged $75-84$, and one in 10 aged 85 and over. Taking all age groups together, mortality in men was significantly higher than in women $\left(\chi^{2}=7.44, p<0.01\right)$. Taking both sexes together, there was no significant relationship between age and death.

MEDICAL FACTORS

The influence of medical factors observed at the time of the fall on mortality within one year of the index fall is summarised in Table 3 .

\section{MOBILITY}

Subjects were divided into those who were able to walk unsupported outdoors, or indoors only; and those unable to do so. Only one in every 15 subjects who were fully mobile outdoors before the index fall died in the succeeding year, compared with one in four of those who were mobile indoors only, and one in two of those who were immobile or dependent. The difference in mortality between those able to walk unsupported indoors or outdoors and those unable to do so was significant $\left(\chi^{2}=13 \cdot 54\right.$, $\mathrm{p}<0 \cdot 01$ ).

\section{B A L A N CE}

Subjects were divided into groups according to their response to the sternal pressure test. ${ }^{2}$ A normal

Table 2 Age and sex of fallers and controls related to mortality in the year after the index fall

\begin{tabular}{|c|c|c|c|c|}
\hline \multirow[b]{2}{*}{ Sex } & \multirow[b]{2}{*}{$\begin{array}{l}\text { Age groups } \\
\text { (years) }\end{array}$} & \multirow[b]{2}{*}{$\begin{array}{l}\text { No. of } \\
\text { fallers and controls }\end{array}$} & \multicolumn{2}{|c|}{ Mortality } \\
\hline & & & $\begin{array}{l}\text { No. of } \\
\text { fallers }\end{array}$ & $\begin{array}{l}\text { No. of } \\
\text { controls }\end{array}$ \\
\hline Men & $\begin{array}{l}65-74 \\
75-84 \\
85 \text { and over }\end{array}$ & $\begin{array}{r}7 \\
10 \\
3\end{array}$ & $\begin{array}{l}2 \\
5 \\
3\end{array}$ & $\begin{array}{l}0 \\
1 \\
0\end{array}$ \\
\hline Women & $\begin{array}{l}65-74 \\
75-84 \\
85 \text { and over }\end{array}$ & $\begin{array}{l}15 \\
60 \\
30\end{array}$ & $\begin{array}{r}3 \\
12 \\
7\end{array}$ & $\begin{array}{l}1 \\
3 \\
3\end{array}$ \\
\hline
\end{tabular}

Table 3 Influence of medical status at the time of fall on mortality in the year after index fall

\begin{tabular}{|c|c|c|}
\hline & No. of subjects & No. who died \\
\hline $\begin{array}{l}\text { MOBILITY BEFORE FALL } \\
\text { Outdoors } \\
\text { Indoors unsupported } \\
\text { Indoors unsteady/immobile }\end{array}$ & $\begin{array}{l}46 \\
50 \\
29\end{array}$ & $\begin{array}{r}3 \\
14 \\
15\end{array}$ \\
\hline $\begin{array}{l}\text { BALANCE } \\
\text { Normal } \\
\text { Abnormal }\end{array}$ & $\begin{array}{l}38 \\
77 \\
\text { (10 no information) }\end{array}$ & 30 \\
\hline $\begin{array}{l}\text { GAIT } \\
\text { Normal } \\
\text { Abnormal }\end{array}$ & $\begin{array}{l}40 \\
85\end{array}$ & $\begin{array}{r}3 \\
29\end{array}$ \\
\hline $\begin{array}{l}\text { CONTINENCE } \\
\text { Continent } \\
\text { Sometimes or always incontinent }\end{array}$ & $\begin{array}{l}92 \\
33\end{array}$ & $\begin{array}{l}19 \\
13\end{array}$ \\
\hline $\begin{array}{l}\text { SET TEST } \\
\text { Good } \\
\text { Moderate } \\
\text { Poor }\end{array}$ & $\begin{array}{l}48 \\
60 \\
17\end{array}$ & $\begin{array}{r}5 \\
17 \\
10\end{array}$ \\
\hline $\begin{array}{l}\text { PREVIOUS FALLS } \\
\text { None } \\
\text { One } \\
\text { More than one }\end{array}$ & $\begin{array}{l}43 \\
18 \\
63 \\
\text { (1 no information) }\end{array}$ & $\begin{array}{r}9 \\
5 \\
18\end{array}$ \\
\hline $\begin{array}{l}\text { PREVIOUS FALLS WITH A 'LONG } \\
\text { None } \\
\text { One } \\
\text { More than one }\end{array}$ & $\begin{array}{l}\text { IE' } \\
107 \\
11 \\
5 \\
(2 \text { no information) }\end{array}$ & $\begin{array}{r}23 \\
5 \\
4\end{array}$ \\
\hline $\begin{array}{l}\text { 'LONG LIE' AFTER INDEX FALL } \\
\text { No 'long lie' } \\
\text { 'Long lie' }\end{array}$ & $\begin{array}{r}105 \\
20\end{array}$ & $\begin{array}{l}21 \\
11\end{array}$ \\
\hline $\begin{array}{l}\text { CLASSIFICATION OF FALL } \\
\text { Group } 1 \\
\text { Group } 2 \\
\text { Group } 3 \\
\text { Group } 4\end{array}$ & $\begin{array}{l}35 \\
30 \\
36 \\
24\end{array}$ & $\begin{array}{r}5 \\
8 \\
8 \\
11\end{array}$ \\
\hline
\end{tabular}

response to this test consists of a slight sway of the body only; an abnormal response included stepping back, staggering, falling, or a 'startle' response of the upper limbs. Of 38 fallers whose response was normal, only two died in the following year, while of 77 whose response was abnormal, 30 died $\left(\chi^{2}=17 \cdot 52, \mathrm{p}<0.01\right)$.

GAIT

Subjects were divided into two groups: those whose gait, when examined after the fall, showed a normal and regular stepping pattern with or without a walking aid, and those with an irregular or unpredictable gait and a tendency to clutch or grab. Of the 40 subjects with normal gait, three died in the subsequent year, compared with 29 of the 85 subjects with abnormal gait $\left(\chi^{2}=11 \cdot 56, \mathrm{p}<0.01\right)$.

CONTINENCE

Subjects were divided into those who were fully continent before the index fall and those who were sometimes or always incontinent. Of the $\mathbf{9 2}$ fallers who were continent, 19 died in the following year, and of the 33 who were sometimes or always incontinent, 13 died $\left(\chi^{2}=4.62, p<0.05\right)$.

MENTAL TEST SCORE

Subjects were given the 'set test' ${ }^{3}$ at the time of the 
first interview and scores were graded as good, moderate, or poor. One hundred and eight fallers had good or moderate scores and of these 22 died in the subsequent year; of 17 with a poor score, 10 died $\left(\chi^{2}=11.4, \mathrm{p}<0.01\right)$.

PREVIOUS FALLS

Of the $\mathbf{4 3}$ fallers who had not fallen previously in the year before the index fall, nine died in the succeeding year. By comparison, there were five deaths among 18 subjects with a history of one previous fall, and 18 deaths among 63 subjects with a history of more than one previous fall. The difference in mortality rate between those who had and those who had not previously fallen was not significant $\left(\chi^{2}=0 \cdot 82\right.$, $\mathrm{p}>0.05)$.

\section{FALLS WITH 'LONG LIE'}

A 'long lie' was defined as a period of one hour or longer in which the subject lay on the floor unable to rise after falling. Of the 16 fallers who had had a previous fall with a 'long lie', nine died in the subsequent year, compared with 23 of the 107 who had not had this experience $\left(\chi^{2}=8.43, \mathrm{p}<0.01\right)$.

'LONG LIE' AFTER INDEX FALL

Twenty fallers lay on the floor for more than one hour after the index fall. Of these, 11 died in the subsequent year, compared with 21 of 105 who did not have this experience. This difference was significant $\left(\chi^{2}=10 \cdot 80, \mathrm{p}<0 \cdot 01\right)$.

CLASSIFICATION OF FALLS

Falls were classified into four groups, a modification of the classification of Brocklehurst. ${ }^{4}$

Group 1 included all falls in which some external object played a part, both those due to environmental hazards and those in which there was a failure to negotiate an object.

Group 2 included all falls which occurred during a change of posture or a relative movement of the head and body.

Group 3 comprised unexpected and unexplained falls while walking.

Group 4 included those falls which could not be otherwise classified because of lack of information, as well as a few associated with an epileptic fit or the onset of a stroke.

The lowest mortality, $14 \%$, was in group 1 falls in which an environmental factor was involved. The mortality in groups 2 and 3 was nearly twice as high, while the highest mortality was in the small miscellaneous group 4, which included a number of subjects with cerebral vascular disease. The difference between group 4 and the rest was statistically significant.

FURTHER FALLS

Further falls in surviving fallers and in controls were recorded at the three-month and twelve-month
Table 4 Further falls by fallers and controls at three months and twelve months after index fall

\begin{tabular}{llllll}
\hline & \multicolumn{2}{l}{ Three months } & & \multicolumn{2}{l}{ Twelve months } \\
\cline { 2 - 3 } \cline { 6 - 6 } \cline { 5 - 6 } & Fallers & Controls & & Fallers & Controls \\
\hline One fall & 18 & 8 & & 20 & 18 \\
Two-five falls & 17 & 2 & & 36 & 16 \\
More than five falls & 9 & 1 & 9 & 2 \\
No falls & 69 & 112 & & 28 & 80 \\
Dead & 12 & 1 & & 32 & 8 \\
\hline
\end{tabular}

follow-up visits (Table 4). All but 28 of the fallers fell again at least once in the year after the index fall and 45 of them, half of the survivors, fell more than once. By contrast, two-thirds of the controls had no falls in the year following the index fall, and only 18 had more than one fall. These differences were significant $\left(\chi^{2}=31 \cdot 12, \mathrm{p}<0 \cdot 01\right)$.

Since falls occurred in the three-month follow-up period in both fallers and controls, and since recall in this period was believed to be good, the opportunity was taken to determine which factors in both fallers and controls were associated prospectively with falls. The results are shown in Table 5. There were proportionately more falls in women than in men, and in those aged 75 and over than in those under 75 . However, the number of falls in men and in those under 75 was small, and the differences were not

Table 5 Falls in the three-month follow-up period (fallers and controls combined)

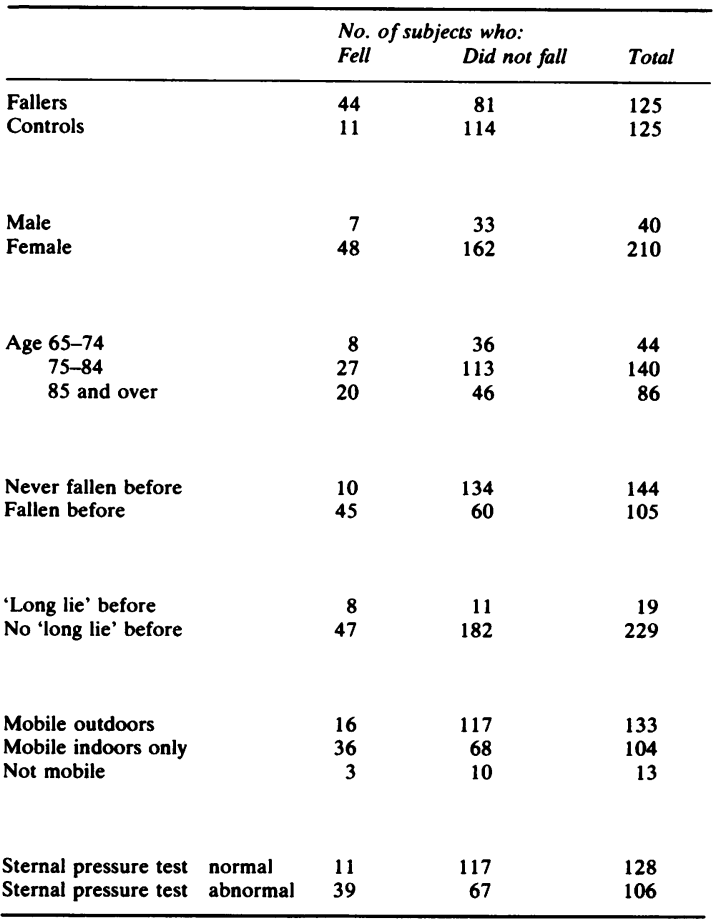


statistically significant. There were, however, significant associations between falls in the three-month observation period and the following: previous fall(s); previous fall with 'long lie'; inability to walk outdoors independently; and abnormal response to 'push test'.

FUNCTIONAL CHANGES

Changes in dependency, mobility, and continence of survivors in the year after the index fall are summarised in Table 6. A 'change' meant a change of grade from that recorded at the initial interview, to that recorded the day before the index fall, for example, from 'mobile outdoors unsupported' to 'mobile indoors unsupported'. Change of functional capacity within the same grade was not recorded. Twelve fallers and six controls became more dependent after one year, a significant difference $\left(x^{2}=3.92, p<0.05\right)$. A higher proportion of fallers than of controls showed reduced mobility after one year, but the difference was not significant. Thirteen fallers and three controls became more incontinent, a significant difference $\left(\chi^{2}=7 \cdot 97, \mathrm{p}<0.01\right)$.

\section{USE OF RESOURCES}

The use of institutional resources by fallers and controls in the year after the index fall is shown in Table 7. Three times as many fallers as controls spent periods in hospital and fallers used twice as many hospital bed-weeks. On average each faller used one more hospital bed-week in the year after the fall than did the control. One faller entered a residential home one week after the index fall and remained there for the rest of the year; in the same time no control living

Table 6 Functional changes in surviving fallers and controls at three months and twelve months after index fall

\begin{tabular}{lccllr}
\hline & \multicolumn{2}{l}{ Three months } & & \multicolumn{2}{l}{ Twelve months } \\
\cline { 2 - 3 } \cline { 5 - 6 } \cline { 5 - 6 } & Fallers & Controls & & Fallers & Controls \\
\hline More dependent & 7 & 5 & & 12 & 6 \\
Less mobile & 20 & 12 & & 21 & 20 \\
More incontinent & 5 & 0 & & 13 & 3 \\
No. of survivors & 113 & 123 & & 93 & 117 \\
\hline
\end{tabular}

Table 7 Use of institutional resources by fallers and controls at three months and twelve months after index fall

\begin{tabular}{lllllll}
\hline & \multicolumn{2}{l}{ Three months } & & \multicolumn{2}{l}{ Twelve months } \\
\cline { 2 - 3 } & Fallers & Controls & & Fallers & Controls \\
\hline Periods in hospital & 18 & 6 & & 36 & 12 \\
Hospital bed-weeks & 93 & 33 & & 265 & 114
\end{tabular}

\begin{tabular}{lllll}
$\begin{array}{l}\text { *Entered residential } \\
\text { home }\end{array}$ & 0 & 0 & 1 & 0 \\
$\begin{array}{l}\text { "Residential home } \\
\text { bed-weeks }\end{array}$ & 0 & 0 & 51 & 0 \\
\hline
\end{tabular}

*These figures exclude those already living in residential homes at the time of the index fall. at home entered a residential home. Domiciliary services were used by more fallers than controls, but details are not available.

\section{Discussion}

Factors significantly associated with excess mortality in the year after the index fall were male sex; abnormalities of gait and balance (that is, abnormal gait, abnormal response to sternal pressure, and not being independently mobile); and indications of concurrent illness (that is, 'long lie' after previous fall, 'long lie' after index fall, incontinence of urine, impaired performance on set test, and group 4 falls).

Factors which were not associated with excess mortality included age and history of previous falls.

The excess mortality in male fallers reflects the generally higher mortality rate in old men. In the control group the mortality of men was lower than that of women, but the number of deaths was small and this could have been a chance finding.

The four factors grouped as 'abnormalities of gait and balance' may represent a single abnormality, namely defective balance. When balance is faulty, for whatever reason, gait is abnormal, independent mobility is lost, and repeated falls occur.

The five factors grouped as being 'indicative of concurrent illness' may represent a single related abnormality which might be described as 'central slowing', or there may be two components representing, respectively, physical and mental retardation.

In an attempt to identify the relative contribution of each factor to the excess mortality, a statistical method of cross-validatory choice was used..$^{5} \dot{ }$ The implementation of the method involved the construction of a 'rooting-tree' by unrestricted sequential splitting of the data, followed by a cross-validatory selection of a preferred cut-off value which was applied to the result of the splitting. The analysis showed that impaired mobility was the only significant mortality factor.

FURTHER FALLS

As indicated above, the factors predictive of further falls included previous falls, especially those associated with a 'long lie'; inability to walk outdoors independently; and an abnormal response to the simple sternal pressure test. These are all readily identifiable by a lay observer and this makes prediction of a high risk of falling a very straightforward matter. It can be concluded that those aged 75 and over, especially women, who have fallen before and who are not now independently mobile, are at high risk of sustaining further falls. FUNCTIONAL CHANGES The deterioration in mobility, independence, and continence in surviving fallers was greater than that in surviving controls, so that some of those fallers 
who did not die in the follow-up year were nevertheless on a downward path.

USE OF RESOURCES

Although surviving fallers used more hospitals and residential homes than surviving controls, the differences were not great, and it is clear that the burden of caring for and supervising this high-risk group fell largely on their families, with support from the community services.

\section{Conclusion}

Falls in people aged 65 and over at home were associated with high mortality, high morbidity, and high utilisation of resources. The high mortality was not directly caused by the falls, except perhaps in a very few of the early deaths, and was not associated with fractures or episodes of hypothermia. The data are consistent with the view that many who fall are ill people with limited mobility and impaired mental function. The extent to which the fall accelerates what is already for many a rapidly deteriorating process cannot be determined. It would, however, seem desirable that further falls should be prevented if at all possible in these patients. Fortunately, it is possible to identify readily those at highest risk of death and of further falls: they are predominantly people aged 75 and over who are housebound as a result of lack of mobility. A concentrated effort to prevent falls in this group may contribute to reducing the very high mortality associated with falls in old people at home.

We thank the general practitioners, the patients, and the controls. The study was supported by a grant from the Department of Health and Social Security.

Reprints from Professor Bernard Isaacs, Department of Geriatric Medicine, Hayward Building, Selly Oak Hospital, Birmingham B29 6JD.

\section{References}

${ }^{1}$ Wild D, Nayak USL, Isaacs B. A study of falls in old people at home. Report to the Department of Health and Social Security, 1980.

${ }^{2}$ Obonyo T, Murphy J. The sternal pressure test: a clinical test of balance. Department of Geriatric Medicine, University of Birmingham (in press).

${ }^{3}$ Isaacs B, Akhtar AJ. The set test: a rapid test of mental function in old people. Age Ageing 1972; 1: 22-6.

${ }^{4}$ Brocklehurst JC, Exton-Smith AN, Lempert-Barber SM, Hunt LP, Palmer MK. Fracture of the femur in old age: a two-centre study of associated clinical factors and the cause of the fall. Age Ageing 1978; 7: 7-15.

${ }^{5}$ Stone M. Cross-validatory choice and assessment of statistical predictions. J R Stat Soc 1974; B 36; 111-47.

${ }^{6}$ Mabbett A, Stone M, Washbrook J. Cross-validatory selection in differential diagnosis. $J R$ Stat Soc 1980; C (in press). 